\title{
AVALIAÇÃO ULTRA-SONOGRÁFICA PELO MÉTODO DE GRAF NO QUADRIL INFANTIL
}

Marcos Almeida Matos*

Trabalho realizado na Escola Bahiana de Medicina e Saúde Pública e Santa Casa de Misericórdia da Bahia, Salvador, BA.

*Correspondência: Rua Rodolfo Cavalcante, 196, apto. 1701, Salvador, BA, Cep: 41750-080 malmeidamatos@ig.com.br

\begin{abstract}
RESUMO
Oвjetivos. A ultra-sonografia realizada pelo método de Graf é importante exame na condução da displasia do quadril, entretanto, sua interpretação é examinador dependente. $\mathrm{O}$ objetivo do estudo foi verificar a confiabilidade e reprodutibilidade deste exame por examinadores com variados graus de experiência.

Métodos. Cinco imagens ultra-sonográficas de um quadril normal foram avaliadas por treze examinadores. Os valores dos ângulos alfa e beta foram avaliados por ANOVA e a concordância foi obtida pelo coeficiente de correlação intraclasse (CCI). Resultados. A média de alfa foi $37,32^{\circ}(\mathrm{II}, 12)$ e de 42,05 $(10,49)$ para beta. Houve erro interobservador de 7,68 e intraobservador de 17,650 para o ângulo alfa. Obteve-se erro intra-observador de $17,65^{\circ}$. para o ângulo alfa e de $17,63^{\circ}$. para beta. Houve erro interobservador de $7,68^{\circ}$. para o ângulo alfa e $17,21^{\circ}$. para beta. O CCl intra-observador foi 0,18 para alfa e 0,29 para beta; o CCl interobservador foi -0,02 para alfa e 0,30 para beta.

Conclusäo. A ultra-sonografia do quadril pelo método de Graf é importante exame auxiliar na displasia do desenvolvimento do quadril, entretanto não deve ser usada isoladamente, pois sua interpretação não tem alta confiablildade, especialmente para observadores inexperientes.
\end{abstract}

Unitermos: Quadril. Diagnóstico. Ultra-som. Reprodutibilidade. Confiabilidade.

\section{INTRODUÇÃo}

Desde a primeira publicação por Graf em 1980', a ultrasonografia do quadril ganhou larga aceitação como principal método de triagem, diagnóstico e monitoramento do tratamento da displasia do desenvolvimento do quadril (DDQ) em crianças ${ }^{2}$. O método estático introduzido por Graf' e a avaliação dinâmica preconizada por Harcke et al. ${ }^{3}$ permanecem os mais amplamente utilizados ${ }^{2,4}$.

Tendo em vista que o diagnóstico e tratamento de quadris displásicos dependem de correta interpretação do ultra-som, há necessidade de quantificar o poder diagnóstico das medidas ultrasonográficas na prática clínica do ortopedista geral.

O objetivo deste trabalho é avaliar a reprodutibilidade e confiabilidade da ultra-sonografia do quadril quando realizada por imagenologistas e interpretada por ortopedistas de variados graus de experiência.

\section{Métodos}

O estudo foi realizado no Serviço de Ortopedia e Traumatologia da Escola Bahiana de Medicina e Santa Casa de Misericórdia da Bahia, tendo obtido aprovação do Comitê de Ética em Pesquisa da instituição.

A ultra-sonografia foi realizada por ultra-sonografista experiente em quadril infantil utilizando aparelho com transdutor linear de $7 \mathrm{MHz}$. Cinco imagens ultra-sonográficas de um único paciente com três meses de idade e quadris considerados clínica e ultrassonograficamente normais foram analisadas por três avaliadores com alto nível de experiência neste exame, sendo que todos concordaram que as imagens tinham excelente padrão de qualidade e encontravam-se absolutamente dentro da normalidade. Estas cinco imagens foram plotadas em uma ficha padrão que continha também exemplo da realização das medidas dos ângulos alfa e beta pelo método de Graf'.

Para a interpretação das imagens foram selecionados seis ortopedistas com Título de Especialista da Sociedade Brasileira de Ortopedia e Traumatologia (SBOT) e sete residentes de ortopedia da Santa Casa de Misericórdia da Bahia que estavam cursando o segundo ano. Estes médicos assistiram a aula sobre mensuração dos ângulos alfa e beta pelo método ultra-sonográfico de Graf e, em seguida, receberam as fichas com as cinco imagens. Todos mediram os ângulos alfa e beta e devolveram as fichas devidamente preenchidas.

As fichas foram tabuladas a partir das medidas encontradas para os ângulos alfa e beta de cada examinador e apresentadas em tabelas sob a forma de estatística descritiva. Estas medidas também foram estudadas pelo método de análise de variância (ANOVA). Os parâmetros avaliados foram média, desvio padrão, mínimo, máximo, erro interobservador e intra-observador.

Para verificação da concordância, utilizou-se o coeficiente de correlação intraclasse $(\mathrm{CCl})$, conforme descrito por Bartko em $1966^{5}$. A interpretaçãa do resultado do $\mathrm{CCl}$ seguira aquela preconizada por Landis e Korch ${ }^{6}$. Os coeficientes de concordância menores que zero foram considerados "péssimos", entre 0 a 20 foram considerados "ruins", entre 21 a 40 considerados "fracos", entre 4 I a 60 considerados "regulares", entre 61 a 80 considerados "substanciais" e aqueles entre 8 I a I,00 foram considerados "quase perfeitos". 


\begin{tabular}{lc}
\hline \multicolumn{2}{c}{ Tabela I - Distribuição descritiva para as medidas do ângulo alfa } \\
\hline Dados & Valores \\
\cline { 2 - 2 } Máximo & 60 \\
Múnimo & 10 \\
Média & 37,33 \\
Desvio padrão & 11,12 \\
Número de exames & 5 \\
Número de examinadores & 13 \\
Número de repetições & 65 \\
\hline
\end{tabular}

\begin{tabular}{lc}
\hline $\begin{array}{l}\text { Tabela 3 - Distribuição do erro e do coeficiente de correlação intraclasse } \\
\text { (CCl) para as medidas do ângulo alfa }\end{array}$ \\
\hline Dados & $\frac{\text { Valores }}{7,68}$ \\
\hline Erro interobservador & 17,65 \\
Erro intra-observador & $-0,02$ \\
CClinterobservador & 0,18 \\
CClintra-observador & \\
\hline
\end{tabular}

\section{Resultados}

Todos os examinadores consideraram-se aptos para a realização das medidas e nenhum ângulo deixou de ser medido. Os valores encontrados para o ângulo alfa foram dados em graus e encontram-se distribuídos na Tabela I. Os valores encontrados para o ângulo beta, também em graus, encontram-se distribuídos na Tabela 2. A distribuiçã̃o dos erros e os coeficientes de correlação intraclasse $(\mathrm{CCl})$ para o ângulo alfa encontram-se na Tabela 3. A distribuição dos erros e os CCl para o ângulo beta encontram-se na Tabela 4.

\section{Discussão}

A ultra-sonografia se tornou rapidamente a ferramenta diagnóstica mais difundida para a displasia do desenvolvimento do quadril ${ }^{2,4}$. A despeito disto, a interpretação da ultra-sonografia do quadril infantil necessita perfeito conhecimento das estruturas anatômicas e envolve análise subjetiva da distribuiçãa e textura da amplitude do eco ${ }^{7}$.

O método de Graf está baseado na obtenção de imagens estáticas do quadril no plano coronal'. Estas imagens fornecem as medidas do teto ósseo (ângulo alfa) e do teto cartilaginoso (ângulo beta) do acetábulo. Estes ângulos são então utilizados para classificar o quadril qualitativa e quantitativamente. A mensuração correta destes ângulos requer perfeita identificação da linha de base no ílio, do labrum e do fundo ossificado do acetábulo, ${ }^{\prime, 4}$.

Os observadores escolhidos foram residentes e preceptores de um serviço credenciado pelo Ministério da Educação e pela Sociedade Brasileira de Ortopedia e Traumatologia, pois o objetivo do trabalho foi verificar o valor deste exame entre ortopedistas com variados graus de experiência em displasia do desenvolvimento do quadril. Neste ponto, o estudo mimetizou fielmente a prática clínica cotidiana, pois quase sempre a ultra-sonografia é realizada pelo imagenologista, mas o ortopedista é quem precisa interpretá-la para tomar decisões sobre a correta terapêutica.

\begin{tabular}{lc}
\hline \multicolumn{2}{l}{ Tabela 2 - Distribuição descritiva para as medidas do ângulo beta } \\
\hline \multicolumn{1}{l}{ Dados } & Valores \\
\cline { 2 - 2 } Máximo & 68 \\
Mínimo & 22 \\
Média & 42,05 \\
Desvio padrão & 10,49 \\
Número de exames & 5 \\
Númerode examinadores & 13 \\
Número de repetições & 65 \\
\hline
\end{tabular}

Tabela 4 - Distribuição do erro e do coeficiente de correlação intraclasse (CCl) para as medidas do ângulo beta

\begin{tabular}{lc} 
Dados & Valores \\
\cline { 3 - 3 } Errointerobservador & 17,63 \\
Errointra-observador & 17,21 \\
CClinterobservador & 0,30 \\
CClintra-observador & 0,29 \\
\hline
\end{tabular}

Utilizamos apenas imagens obtidas de um quadril normal para interpretação com o intuito de diminuir a amplitude do erro e a dificuldade da análise. Não utilizamos a classificação de Graf para displasia do desenvolvimento do quadril, mas utilizamos seu método ultra-sonográfico baseado nas medidas dos ângulos alfa e beta para quantificar o erro na medida destes ângulos, ao invés de quantificarmos o erro da classificação.

Em nosso trabalho, a média do ângulo alfa foi de $37,32(11,12)$ e de 42,05 $(10,49)$ para o ângulo beta. Houve um erro interobservador de 7,68 e intra-obsevador de 17,65 para o ângulo alfa. A medida do ângulo beta teve erro interobservador de 17,63 e intraobservador de 17,21. O coeficiente de correlação intraclasse (CCl) interobservador foi de -0,02 (considerado "péssimo") e o CCl intraobservador foi de 0,18 ("ruim") para o ângulo alfa. $\mathrm{O} \mathrm{CCl}$ interobservador foi de 0,30 ("fraco") e CCl intra-observador de 0,29 ("fraco") para o ângulo beta. Estes dados confirmaram que a ultra-sonografia do quadril pelo método de Graf é um exame de difícil interpretação, que permite um erro considerável nas medidas angulares e, por este motivo, não deve ser encarada como padrão ouro no diagnóstico da displasia do desenvolvimento do quadril.

Bar-On² em 1998 realizou estudo de confiabilidade com o método de Graf analisando medidas obtidas por três diferentes ortopedistas em 75 ultra-sonografias de quadris de paciente com 14 semanas de idade. Nesse estudo, o ângulo alfa teve erro intra-observador de $10^{\circ}$ (7 a l2) e erro interobservador de $13^{\circ}$ (8 a 16), sendo que o erro para o ângulo beta não foi quantificado. A classificação de Graf teve concordância intraobservador de 0,6 I ("substancial") e interobservador de 0,57 ("regular"). Quando se tratou de diferenciar quadris normais de anormais, a classificação de Graf mostrou concordância intra-observador de 0,67 ("substancial") e interobservador de 0,57 ("regular"). Quando se consideraram apenas quadris anormais, obteve-se baixo índice de concordância, sendo 0,4I ("regular") intra-observador e 0,28 ("fraco") interobservador. Bar-On² concluiu que a ultra-sonografia tem alta capacidade de diferenciar quadris 
normais e anormais e, por este motivo, serve bem como exame de triagem, entretanto, deve-se utilizar outros métodos para melhorar a sua confiabilidade em quadris displásicos.

Roovers ${ }^{8}$ em 2003 realizou estudo semelhante, porém seus quatro examinadores eram radiologistas. Obteve concordância interobservador de 0,47 ("regular") para a classificação de Graf e a concordância em diferenciar quadris normais de anormais foi de 0,6। ("substancial"). Esse autor concluiu que a ultra-sonografia do quadril é suficiente apenas para o propósito de triagem.

Dias et al. ${ }^{9}$ em 1997 realizaram estudo com cinco observadores experientes em ultra-sonografia do quadril infantil (dois radiologistas pediátricos e três ortopedistas). O coeficiente de correlação intraclasse foi 0,69 ("substancial") intra-observador e 0,65 ("substancial") interobservador para o ângulo alfa. $O$ ângulo beta teve concordância de 0,78 ("substancial") intra-observador e 0, I I ("ruim") interobservador. Nesse mesmo estudo, a concordância dos observadores em identificar os pontos anatômicos essenciais no exame ultra-sonográfico do quadril variou de 0,46 ("regular") para o labrum a 0,68 ("substancial") para o rebordo cartilaginoso.

Jomha et al. ${ }^{4}$ em 1995 realizaram estudo com três observadores: um residente de ortopedia, um ortopedista pediátrico e um radiologista. A concordância para o residente de ortopedia foi de 0, 14 ("ruim") para o ângulo alfa e 0,22 ("fraco") para o beta. O CCl para o ortopedista pediátrico foi 0, I I ("ruim") para o ângulo alfa e 0,5 I ("regular") para o beta. $\mathrm{O}$ radiologista obteve $\mathrm{CCl}$ de 0,89 ("quase perfeito") para 0 ângulo alfa e 0,86 ("quase perfeito") para o beta.

Os dados da literatura confirmam nossos achados. A reprodutibilidade da ultra-sonografia do quadril infantil parece estar ligada diretamente à experiência de quem interpreta este exame. Observadores experientes podem identificar os pontos anatômicos com certeza substancial e, a partir daí, traçar os ângulos alfa e beta com maior confiabilidade 4 . Examinadores inexperientes têm dificuldade em traçar os ângulos, especialmente o ângulo alfa, que é o mais importante para a classificação de Graf. A interpretação da ultra-sonografia do quadril também parece depender de uma combinação de tamanho, qualidade e critérios de seleção da imagem, o que tentamos minimizar utilizando imagens de um único quadril normal. Por este motivo, todos aqueles ortopedistas que trabalham com DDQ devem ser treinados constantemente para familiarizarem-se com este exame.

\section{ConClusÃo}

Nossos dados permitiram concluir que a ultra-sonografia do quadril pelo método de Graf não tem boa reprodutibilidade quando interpretada por ortopedistas gerais, sem ampla experiência com este exame. A despeito do fraco desempenho demonstrado, a ultra-sonografia permite melhor visualização da cartilagem acetabular que o raio $X$, pode ser repetida sem riscos adicionais e pode reduzir a necessidade de exames clínicos repetitivos. Por estes motivos, acreditamos que a ultra-sonografia do quadril permanece importante ferramenta auxiliar no diagnóstico das doenças do quadril infantil, entretanto, quem interpreta este exame deve buscar adquirir experiência e associar seus achados com o exame clínico devido à sua baixa confiabilidade.

\section{Conflito de interesse: não há.}

\section{SUMMARY \\ ULTRASONOGRAPHIC ASSESSMENT OF INFANTILE HIP BY THE Graf Method}

BACKGROUND. Ultrasonography of the hip performed by the Graf method is widely accepted as an important diagnostic and treatment tool for hip dysplasia. This study aims to examine the reliability and reproducibility of the interpretations of ultrasound scans by general orthopedists.

METHODS. Thirteen examiners evaluated five hip ultrasounds of the same normal child. The examiners measured alpha and beta angles according to Graf. Statistical analysis was performed by variance analysis (ANOVA) and agreement was calculated and expressed as the intraclass correlation coefficient (ICC).

RESULTS. The alpha angle mean was $37.32^{\circ}(11$. I 2) and the beta angle mean was $45.05^{\circ}(10.49)$. Error of the intra-observer was 17.65 for the alpha angle and 17.63 for the beta. Error of the inter-observer was 7.68 for the alpha angle and 17.2I for the beta. ICC intra-observer was 0.18 forthe alpha angle and 0.29 for the beta. ICC inter-observerwas -0.02 for the alpha angle and 0.3 for the beta.

CONCLUSIONS. Ultrasound of the infantile hip using the Grafmethod is an important tool for the assessment of developmental dysplasia of the hip, however, it must be emphasized that preciseness of interpretation requires training and frequent use. [Rev Assoc Med Bras 2006; 52( (1): 53-5]

KeY WORDS: Hip. Diagnosis. Ultrasound. Reproducibility. Reliability.

\section{REFERÊNCIAS}

I. Graf R. The diagnosis of congenital hi-joint dislocation by the ultrasonic compound treatment. Arch Orthop Trauma Surg 1980;97: | 17-33

2. Bar-On E. Ultrassonography of the hip in developmental hip dysplasia. J Bone Joint Surg 1998; 80:321-4

3. Clarke NMP, Harcke HT, McHugh P, Lee MS, Borns PF, MacEwen GD, et al. Real-time ultrasound in the diagnosis of congenital dislocation and dysplasia of the hip. J Bone Joint Surg 1985;67-B:406- 12.

4. Jomha NM, Mclvor J, Sterling G. Ultrasonography in developmental hip dysplasia. J Pediatr Orthop 1995; I 5: I 01 -4.

5. Bartko J). The intraclass correlation cefficient as a measure of reliability. Psycol Rep 1966;19:3-11.

6. Landis RJ, Koch GG. The measurement of observer agreement for categorical data. Biometrics 1977;33: I 59-74.

7. Shung KK. Ulrasonic characterization of biological tissue. J Biomech Eng 1985; | 07:309- 14.

8. Roovers EA. Ultrassonography screening for developmental dysplasia of the hip in infants. Reproducibility of assessment made by radiographers. J Bone Joint Surg 2003;85:725-30.

9. Dias JJ, Thomas IH, Lamont AC, Mody BS, Thompson JR. The reliability of ultrassonographic assessment of neonatal hips. J Bone Joint Surg 1993;75:479-82.

Artigo recebido: 29/07/04

Aceito para publicação: 09/12/04 